Wearing, S.L. \& Archer, D. (2002). Challenging interpretation to discover more inclusive models: The case of adventure tour guiding. World Leisure Journal, 44 (3), pp. 4353.

\title{
Challenging interpretation to discover more inclusive models: The case of adventure tour guiding
}

\author{
by
}

Stephen Wearing and David Archer

Dr Stephen Wearing,

Senior Lecturer,

School of Leisure, Sport and Tourism,

University of Technology, Sydney.

P.O Box 222 Lindfield NSW 2070 Australia.

Ph 6129514 5432, s.wearing@uts.edu.au

David Archer,

Research Assistant,

School of Leisure, Sport and Tourism,

University of Technology, Sydney.

P.O Box 222 Lindfield NSW 2070 Australia.

Ph 6129514 5145, david.archer@uts.edu.au 


\begin{abstract}
Participation in higher risk outdoor adventure activities has increased significantly in recent years and this trend is expected to continue in the foreseeable future. It is suggested in this paper that the general focus of much current interpretive practice excludes those elements central to the outdoor adventure experience, namely, risk, the experience of nature in its rawest form, and the ability to interact with nature with no imposed values. This paper puts forth the argument that if the underlying objectives of interpretation relate to the social value of the quality of interaction with nature, the ethics of care for nature and a greater appreciation of the consequences of human action on nature and local cultures, then new approaches need to be introduced. The paper discusses how in allowing outdoor adventure guides to become interpreters we may begin to develop a more inclusive model for outdoor interpretation.
\end{abstract}

Keywords: interpretation, adventure guiding, interaction, outdoor recreation, national parks 
Introduction

In recent years, many outdoor recreation agencies have identified a changing 'visitor type' to protected areas and national parks, with high-risk adventure based activity participants comprising a rapidly growing market segment (cf. Bowers \& Hoffman, 1999; Chavez, 1999; Cordell et al, 1999). This growing market segment generally visits national parks on package tours and/or guided trips and most often in small groups. As increasing numbers are attracted to adventure based recreation activities such as canoeing, rock climbing, abseiling, white-water rafting and cross country skiing there has been a need to ensure that nature is not only viewed as a background to the adventure activity, but is also a central part of the process of the experience.

The reasons for the rise in participation rates in adventure based activities appear to relate closely to increases in free leisure time, improvements in transportation, and technological developments in equipment, which have made these activities safer and more comfortable to participate in. An adventure based experience offers the individual an escape from urban, working and existing social structures where one can find specific experiences which affect our quality of life. The way in which outdoor recreation agencies meet this demand is of great significance as the education of adventure recreationists offers increasing potential for the support of conservation approaches to national parks. By incorporating interpretive activities into outdoor recreation management it is possible to allow for the combining of activities and interactions which Graham (1985) notes as the 'gymnasium and the theatre' into interpretation.

Traditionally, however, adventure recreationists and activities have been excluded from most park interpretive programs (Roggenbuck \& Williams, 1991). Park managers have typically focused interpretation on built facilities such as visitor centres to provide security for visitors, to control visitors and their behaviour, and to reinforce a strict set of values that park mangers wish to impart on visitors. It may be argued that the adventure guide is trying to provide the antithesis of this for the client. Elements of importance to the adventure activity participant such as risk, the direct experience of nature in its most base form, the ability to commune with nature with no imposed values and a means to escape everyday life, all appear not to fit within the focus of current interpretive programs in protected areas. In this paper we seek to reflexively examine current interpretive practice and its use for adventure guided experiences. We identify the Western impulse to control and capture nature through varying curatorial practices as limiting the value of the interpretive experience and leading to the exclusion of areas such as adventure guided experiences. Through an examination of the synthesis of current interpretive practice and adventure experiences we seek to create an alternate, more inclusive approach related to nature and human experience within protected area interpretation. In doing so we attempt to outline the potential enrichment of participation knowledge and experience.

Central to the arguments put forth in this paper is the recognition that current directions in interpretation are towards the conservative political agendas of preservation/conservation attached to very limited views of nature in capitalist economies. We argue that such a policy trajectory isolates areas such as adventure guides and experiences, and thus interpretation has failed to deliver to this visitor audience. Additionally, if actions towards ecological sustainable protected areas are to be achieved, it is suggested that adventure tourism needs to be accommodated. If the underlying objectives of interpretation relate to the social value of the 
quality of interaction with nature, the ethics of care for nature, and a greater appreciation of the consequences of human action on nature and local cultures, then new approaches need to be introduced. This paper examines how in allowing adventure guides to become interpreters we may find a way forward.

\section{Commercialisation and professionalisation in outdoor recreation}

The economic benefit of encouraging tourism in protected areas and national parks has been recognised for some time as creating a wider market and larger diversity of visitor types, thus the management and protection of the environments are being challenged from their increasing use. Protected area managers are being forced to confront a number of new issues and focus on a conservation approach with more accountability in terms of income returned. The response to this pressure increasingly is to find more effective and efficient ways of meeting public needs while managing with fewer resources. National competition policy is forcing a dichotomy between the regulatory functions of the protected area organisation and the commercial functions associated with delivery of public services (Wearing \& Bowden, 1998).

Access to outdoor experiences through commercial providers is an increasingly more common form of participation in outdoor recreational activities and before 'customers' will participate, most desire a guarantee of 'value for money' from the provider. The provider needs to profit from the client in order to ensure the survival of their business and to attract and encourage clients to return. However, the commercialisation of outdoor activities has implications for the experiences of clients. The introduction of professionalism, for example, gives risk management priority over experiences, and accreditation systems based on standards driven by 'professionalisation' arise from the legal liability associated with client/provider relationships. Provider's focus on the security of the client, but this in turn can reduce the risks, an element which, in part, is the basis of change and interaction found in the outdoors and is coveted by most if not all adventure enthusiasts.

The potential for competition in the commercial functions of national parks is being exploited with the aim of driving greater innovation and customer focus in the provision of public services. Protected area organisations are being required to reform their accounting systems, price 'user-pay' services on a commercial basis, consider the 'user-pay' option for other services more seriously and outsource some specialist functions. Governments are using a number of mechanisms to produce increased accountability for use of resources, which restricts spending on areas like national parks and specifically interpretation programs (Archer \& Wearing, 2002).

However, this debate can limit the opportunities that might be availed through looking at other approaches to interpretation. There appears to be a need to develop a more proactive, longterm approach to interpretation that is not only focused on trying to protect parks. If interpretation is just seen as a controller of social behaviour so as to allow management to offset costs, given that a primary function of national parks services is to control behaviour in designated areas as to preserve their natural state, it then becomes too limited.

\section{The role of the 'guide' in adventure recreation}


Wilderness camping, backpacking, abseiling, climbing, caving, orienteering, canoeing, rafting, pack animal trips, sailing and cross country skiing are some of the activities that are considered adventure pursuits. Usually an adventure must have some element of uncertainty, possibly the outcome is unknown or the setting is unfamiliar. The uncertainty stems from certain risks that are inherent to the activity. The participant is placed in a situation where learning is optimal, be that intra or interpersonally, and generally done in a natural setting. Within this environment the opportunity to impact on the individual is high. Given the close influence of instructors or guides and the exposure to these natural environments there is an opportunity in these experiential learning settings to increase interpretation of these environments. Given the time that is involved in adventure activities i.e. travelling there, returning and camping or drifting on a river between rapids, waiting for your turn to climb, belaying someone, all of these times allow for framing and reflecting the experience as a form of nature interpretation. If these opportunities are taken, then an appreciation for nature can easily become a part of outdoor adventure programs and the experience contributes to the development of self in a way that is not controlled but allows the individual to examine their relationship with nature.

One potentially effective facilitator of this experience is the adventure guide, who traditionally has not been a person perceived to be an interpreter. One reason for this is because the interpreter is presented as distinct from an explicitly pedagogical function in that the provision of skills fostered through the explanation of equipment and technique is coupled with, and providing, thrills. In today's post industrial Western society there has unfortunately been a growing tendency to extrinsically value natural environments and outdoor experiences. This can mean that people encountering nature in commercially orientated groups are not often exposed to interpretation of those environments to the fullest degree possible, while people experiencing traditional interpretive programs are not allowed the freedom to explore their relationship with nature, and the values they might wish to apply to it.

However, issues existing in adventure guiding may have prevented the integration of adventure guides as interpreters. For example across many parts of the world, adventure activity guides appear primarily to be males and 'since the outdoor leader is a crucial factor in establishing group normative behaviour, the program can either foster or prevent the development of androgynous goal' (Knapp, n.d: 16). Yet, does the gender of the interpreter have any influence on the experience being gained or the way information is delivered? It has been argued that the traditional, masculinized perspectives which construct tourism and leisure experiences have objectified the destination as a place which is presented, authentic or otherwise, to the tourist for his gaze (Wearing \& Wearing, 1988; Wearing \& Wearing, 1992; Wearing \& Wearing, 1996).

Most outdoor adventure programs provide numerous opportunities for interpretation. These can stem from opportunities directly related to the activity, i.e. the river or the rock face to more indepth information on the ecosystems that exist within these elements. Dawson (1992) maintains interpretation is at optimal effectiveness when four factors operate together: the audience, the interpreter, the activity design, and the facility itself. The teacher or interpreter has some control factors and has the ability to combine them effectively. The current problems of emphasis on equipment, competition and high-skill level could be refocussed or be transferred into an interpretation context. If nature remains as the backdrop for the activity with primarily a utilitarian value, the adventure program can lose its relationship with nature; therefore the natural environment becomes a means to an end. The opportunity to develop an understanding, respect and appreciation for nature can be lost, however, if an opportunity is 
taken to include interpretation and change the emphasis of the more traditional masculine valuing of the experience inherent in much guiding, some opportunities exist for change.

The need to be in control may be one reason why interpretation through adventure activities is not common. The control of the activity may prevent the experience moving towards a person being in nature, the creation of space and being in control of that space by a guide, thereby limiting the freedom of the participant to explore their relationship with nature. The male focus on a 'quest for adventure' (Ewert, 1989) may have limited his ability to be an interpreter while a patriarchal society has limited women (Scraton, 1994: 252) and the feminine to roles that do not include adventure guiding, and thus, have excluded a set of values that may influence the identities of the participant (cf. Kaplin, 1990: 364) in a way that allows a closer interaction with nature, and that are more closely aligned to the objectives of interpretation. The synthesis of interpretation and adventure experiences may provide us with an opportunity to move both areas into the new century. It is the balancing of the elements and concepts of interpretation with those of a more 'feminised' adventure experience that appears to offer a positive way forward.

\section{Interpretation and outdoor recreation}

Recognition of the role of interpretation has been fundamental to the concept of national parks and environmental protection for decades. Freeman Tilden (1977), in providing one of interpretations most recognised definitions states that it is 'an educational activity which aims to reveal meaning and relationships through the use of original objectives, by first-hand experience, and by illustrative media, rather than simply to communicate factual information' (Tilden, 1977:8). A focus on the dimensions of visitor experience reveals that the visitor is concerned not with simply looking at a setting or object, but with feeling and realising some of its value. In this way, interpretation is oriented towards a visitor's cognitive and emotional state in order to raise awareness, enhance understanding, and hopefully, clarify or enlarge each participant's perspective and attitude (Wearing \& Neil, 1999). Thus, interpretation is essential to the attainment of conservation goals. Knudson et al (1995) suggest that the primary ulterior motive of agencies and individual interpreters is to lead people to greater concern and intelligent action to sustain the natural and cultural environment in which people live. Interpretation is seen as being important to society as a way of acquainting the population with its life support system - the environment (Beckmann, 1991). It is designed to help tourists broaden their awareness and understanding about the places they visit, and therefore adds to their tourist experience. A well-rounded interpretation program must therefore encompass better public use of parks and must reach a wider audience.

However, there appears to be a growing dilemma for interpretive practice where it is seen to be and is increasingly used as a tool more for controlling the behaviour of the visitor/tourist and their impacts and less as a medium that facilitates and promotes interaction and exchange between the tourist, the host community and nature. This trend can be traced in part to the growing influence of market-driven profit motives and reductions in resources facing most protected area organisations (Archer \& Wearing, 2002). Interpretation is becoming more and more an authoritative act, which for reasons of brevity, directness and audience often appears to speak in singular terms. Such singularity is reductive, it privileges some knowledge over others creating hierarchies not layers of understanding. These issues then raise a number of important questions for interpreters and protected area managers. What are the relations 
between different knowledge practices in interpretation? How are we to explore views of nature that may enable us to move interpretation to a position that enables each individual to establish a relationship with nature, rather then reinforcing the views of the professional educator, the tour operator or the guide?

Since parks are not islands removed from their surrounds, interpretation must relate to the environment as a whole. To achieve this objective the idea of interpretation must be significantly expanded, linking it to the culture and the sociological context of the user while retaining interpretations philosophical alignment to environmental philosophy. For just as interpretation and recreation and tourism experiences can promote a change, or begin to effect an environmental ethic, the contemporary values and attitudes of a society can also exert a profound influence on recreational choice as individuals choose recreational activities which are consistent with their basic outlook on resources, the environment and the quality of life (Jackson, 1986).

The application of sociological analysis of interpretation in protected areas in its cross-cultural context has begun to challenge and influence the practice of interpretation in recent years (Wearing \& Hall, 1998). Nature is socially constructed and protected area organisations provide a space for individual experiences that are in some way related to nature. If these organisations construct the interpretation of nature according to their own cultural backgrounds and values, or those of individual operators and managers, what we will see is the positioning of the park managers (the host's) culture as superior to the 'inferior' other of the tourists home culture and their view of nature; the very foundation of the tourism experience that typifies mass-tourism and which alternative forms such as adventure and ecotourism seek to avoid. National parks and nature then become places for what Urry (1990) terms the tourist gaze (a voyeuristic gaze). The interpretation of nature is perceived as alien and serves to reinforce the dominant values of park management rather than a process of experience. In moving beyond this hegemonic construction, interpretation needs to move towards providing experiences that will enlarge the self and enhance interaction with nature.

\section{Integrating interpretation with adventure guiding and activities}

Recreation and tourism, especially adventure pursuits, are often seen as detrimental to the preservation and conservation of a natural area because of their impacts. The result is often a sharply polarised and conflicting one, oscillating between an exclusive preservationist attitude and one in which access is desired to be unrestricted with minimal (if any) regulation of recreational activities. In order to resolve this bipolarity, protected area managers need to not only develop clear objectives and regulation strategies but also require a fundamental change in peoples' perceptions of parks and the natural environment in general.

However, the ability of interpretation to achieve a shift in the ethos of the individual is not conclusive. A single, one-off interpretive experience cannot be expected to result in transformational change in the opinions, values and awareness of the visitor (Littlefair, Buckley \& Wearing, 2002). Similarly, Hammit (1992) noted that some people feel that interpreters place too much faith in the changes resulting from a 30 minute encounter, arguing that 'educators have long recognised that it may take years of sequenced experiences to achieve some results' (1992: 12). As early as 1949 Aldo Leopold observed that much interpretation fails to address the more immediate conservation values which affect society 
daily in its decision-making (Beckmann, 1987). This may, in some measure, still be the case, however interpretation has developed significantly and to a large extent been accepted as a primary management tool due to its potential to expand our environmental knowledge in a cumulative process.

Similarly, the question as to whether adventure experiences do actually increase concerns for, and attitudes towards, the environment has long been debated. Chavez (1991: 2) points out that 'one of the major philosophical premises of environmental education concerns the value of first-hand involvement with an object.' Tilden's definition of interpretation also points out the importance of first-hand experience as opposed to simply communicating factual information (in Carter 1984). Both of these authors stress the importance of the individuals' involvement in the development of a greater appreciation of natural environments.

A study by Olson, Bowman \& Roth (1984) found that visitor strategies significantly raised levels of knowledge and attitudes towards nature preservation management. Roggenbuck \& Williams' (1991) research on commercial river tour operators on the New River Gorge National River in the USA found that the effectiveness of interpretation was enhanced in the following ways:

1. the amount of interpretation provided by river guides increased following a training session provided by the National Park Service;

2. visitors' knowledge of the area increased following guide training;

3. intentions to visit the park's visitor centres increased following guide training;

4. visitor enjoyment increased following guide training; and

5. the effectiveness of the training program varied according to the experience level of the guides.

Similarly, much research has also been done into the effect of outdoor recreational pursuits on environmental attitudes and whether these effects are of a positive or negative outcome. Research conducted by Dunlap \& Heffernan (1975) suggests that positive effects result in the case of people engaging in 'appreciative' activities where the environment is minimally affected by recreational activities (e.g. camping, hiking) as opposed to 'consumptive' activities such as hunting and fishing (Jackson 1986). Following on from this research, Jackson retested the two relevant hypotheses with minor alterations but using a far more accurate measure for environmental attitudes. Jackson's (1986) results supported the Dunlap-Heffernan hypotheses adding great weight to the argument that outdoor experiences increase environmental awareness thus effecting an improvement in attitudes towards the environment.

Cockrell, Bange \& Roggenbuck (1984) found in their study of rafters that respondents wanted more information about the environment and usually obtained this from the river operators if it was not available from friends and acquaintances. Even with attractive and easily accessible visitor centres the national park service was almost never a source of information for rafters. In this respect the study found that guides have a significant influence over their customers when compared to family, other party members, and other referents. Bange's (1984) research supports this, in finding guides to be very influential both as sources of information and in the development of norms and beliefs in visitors.

There is a large body of research (Markwell \& Weiler, 1998; Harrison 1977, Warder 1988, Fazio 1979) that supports the idea that personal interpretation provided by guides, rangers, or 
interpreters, is more effective than other mediums. Personal communication, personal involvement and personal discovery all lead to personal environmental awareness. This is also seen by Roggenbuck \& Williams (1991) as they suggests that the personal contact is often more effective in altering behaviour. Oliver, Roggenbuck \& Watson (1985) and Roggenbuck \& Berrier (1982) found that personal contact increased the effectiveness of brochure distribution which indicates this contact can improve the effectiveness of other forms of interpretation. A study by Weiler (1991) found that the tour leader, in nature-based tour companies and educational travel programs, plays an important role, possibly constituting the key ingredient.

Chavez (1991) maintains that a major philosophical premise of environmental education concerns the value of first-hand involvement with an object. Direct contact, a central element of guiding, provides unique and required learning opportunities that may not be duplicated elsewhere (Tilden, 1977). One experiment which provided groups with only factual information, as is done with some environmental education programs, had no positive influence on children's attitudes (Morgan \& Gramann, 1989). For programs to be effective in changing attitudes, research indicates that factual information must be accompanied by additional techniques involving modelling or direct contact (Morgan \& Gramann, 1989). Thus, two-way communication and hands-on experiences can be considered important factors.

Outdoor adventure guides allow and enable interaction in ideal interpretive settings. Edwards (1976) and Tilden (1977) both state that interpretation is more effective and enjoyable as a means of communication if the environment involved is a part of the interpretation and Ham (1983) notes that as national parks become more relevant and meaningful, learning benefits are enhanced by active interpretation. These examples serve to demonstrate that interpretive education packaged within outdoor adventure programs offers a vehicle for protected area organisations to further their objectives through interpretation, education and outdoor adventure. In reviewing the literature it becomes clearer that the adventure tour guide has an important role to play in meeting the goals of interpretation. These types of programs require a high degree of interaction between the leader and participants and the use of time.

\section{Towards a synthesis}

This paper has attempted to provide a general overview of our understanding of existing interpretive practice and adventure guiding. Table 1 provides a summary model of what we see to be the existing relationship between the two concepts, with apparent limited overlap between each from a sociological perspective. When represented within sociological concepts a range of problems that limit the ability of nature becomes a major influencing factor in the values, identity and selves of the participant or visitor. The ability of interpretation in its current guise to be inclusive is somewhat limited.

[insert Table 1 here]

The alternative model that we are proposing (Table 2) is dependent on a more equitable distribution of power between existing park interpretation models and adventure guided experiences where interaction occurs in interpretive space. In this model other views of nature are respected and the participant is able to experience aspects of the 'other' view of nature with a view to learning and expanding their views. This shift in the relationships of power 
between park mangers, visitors, adventure guides and participants allows for other views of nature which enables both to interact and to learn from each other with an eventual hybridisation of interpretive practice and an expanded view by both.

The interpretive space and the adventure experience becomes a place for interaction and learning and the participant does not damage or destroy the space but can expand self to allow nature to become a part of self. In this conceptualisation of the interpretive experience, the social interaction between adventure tour participant and tour guide, others within the group, and natural environment forms an exchange of influence that creates a social value of the site for the participant involved that effects a change in self and identity. As such, the behaviour and values of the adventure tour participant have been impacted upon, and they come away from the experience with a changed value for the social and physical environments visited. This experience may also have engendered changes within the field of interaction, such as in representatives of the host community.

This alternative model of protected area interpretation and adventure guided experiences is, in some ways, idealised as it depends on considerable shifts in power and ways of thinking. However, it gives us an approach to creating interpretive experiences and spaces that may provide avenues for both interpretation and adventure guided experiences to move towards alternative procedures and practices and there is evidence of this within both. We see the following challenges for interpretation: 1) it allows other views; 2) it is inclusive rather than exclusive; and 3) it is valuing of difference - in other words it promotes a plurality of experiences.

[insert Table 2 here]

\section{Conclusion}

In reviewing the current use of interpretation as a management tool for protected area organisations we can make some general observations:

- It is increasingly reductive in the sense that economic and commercial pressures mean that it is often reduced to the lowest common denominator of understanding

- It is prescriptive in that the interpreter or guide assumes the role of 'expert' and interpretation is more and more being used to control behaviour rather than inspire, educate and facilitate social and cultural interaction

- Much current interpretive practice privileges some knowledge over others, and creates hierarchies not 'layers of understanding'

It has been argued in this paper that in protected area management a singular view of natural areas conservation has been given high priority which has resulted in interpretation being used to regulate for conservation rather than allowing it to reach its full potential. The adventure tour guide is in a powerful position to play the role of interpreter in such a way that progresses interpretive practice to the stage where it allows the individual, each with their own set of social and cultural values, to explore their relationship with the environment. The adventure tour participant is encouraged by elements within the interpretive 'space' to interact with and experience the real environment and go beyond the contrived and artificial. Rather than 
seeking to passively gaze at sites and attractions, the adventure tour participant is viewed as an agent actively looking for interaction with and learning about the 'other'.

The future demands debate and response to avoid impulsive or market-driven decisions that affect all with little consideration. This paper has attempted to constructively add to such debate. The increase in outdoor enthusiasts and participants, articulated here in the context of adventure based guiding and experiences, should be embraced with enthusiasm under the umbrella of interpretation and viewed as another potential audience for the appreciation and protection of nature and the outdoors.

\section{References}

Archer, D. \& Wearing, S. (2002). Interpretation and marketing as management tools in national parks: insights from Australia. Journal of Leisure Property, 2 (1), 29-39. 
Bange, S. (1984). Normative Influences and Processes among New River Gorge Boaters, Unpublished masters thesis, Virginia Polytechnic Institute and State University, Blacksburg.

Beckmann, E. (1991) Environmental interpretation for education and management in Australian national parks and other protected areas, $\mathrm{PhD}$. Thesis, University of New England.

Beckmann, E. (1987). Interpretation and Heritage Area Management: An Australian Perspective. Heritage Communicator, 1 (2), 5-8.

Bowers, R. \& Hoffman, R. (1999). Whitewater recreation trends in the United States, in Cordell, $\mathrm{K}$. et al. (Eds)., Outdoor recreation in American life: A national assessment of demand and supply trends. Sagamore.

Carter, W. (1984). Nature Conservation, Wilderness and Interpretation, in Martin, V. (Ed)., Wilderness, Wisconsin: Lorien Press.

Chavez, D. (1999). Mountain biking - a rapidly growing sport, in Cordell, K. et al. (Eds)., Outdoor recreation in American life: A national assessment of demand and supply trends. Sagamore.

Chavez, D. (1991). Environmental Education: A New Model, WLRA Congress, UTS Sydney Australia 16th - 19th July.

Cockrell, D., Bange, S. \& Roggenbuck, J. (1984). Normative influence through interpretive communication. Journal of Environmental Education 15 (4), 20-26.

Cordell, K. et al. (Eds) (1999). Outdoor recreation in American life: A national assessment of demand and supply trends. Sagamore.

Dawson, L. (1992). How to Interpret Natural and Historical Resources, WWF Latin America and Caribbean Program WWF, USA.

Dunlap, R. \& Heffernan, W. (1975). Outdoor recreation and environmental concern: An empirical examination. Rural Sociology 40, 18-30.

Edwards, Y. (1976). Interpretation - What Should It Be? Journal of Interpretation, 1 (1), 4.

Ewert, A. (1989). Outdoor Adventure Pursuits: Foundations, Models and Theories. Publishing Horizons Inc.

Fazio, J. (1979). Communicating With The Wilderness User, University of Idaho, College of Forestry, Wildlife and Range Experiment Station Bulletin No. 28, Moscow, 65.

Graham, R. (1985). Marine Recreation and Underwater Parks: Recreation Use to Enhance Conservation Ends, in Len, J. \& Graham, R. (Eds)., Marine Parks and Conservation: Challenge and Promise. National and Provincial Parks Association of Canada, 133-143. 
Ham, S. (1983). Cognitive psychology and interpretation: synthesis and application. Journal of Interpretation, 8 (1), 11-27.

Hammitt, W. (1992). Cognitive processes involved in environmental interpretation. Journal of Environmental Education, 11-15.

Harrison, A. (1977). Getting Your Story Across - Interpreting the River Resource, in Proceedings: River Recreation Management and Research Symposium, USDA Forest Service Gen. Tech. Rep. NC-28, 125-138.

Jackson, E. (1986). Outdoor recreation participation and attitudes to the environment. Leisure Studies, 5 (1), 1-23.

Kaplin, C. (1990). Pandora's box: subjectivity, class and sexuality in socialist feminist criticism, in Lovell, T. (Ed)., British Feminist Thought: A Reader, Blackwell.

Knapp, C. (n.d). Escaping the gender trap: The ultimate challenge for experiential educators, unidentified.

Knudson, M., Cable, T. \& Beck, L. (1995). Interpretation of Cultural and Natural Resources. State College, PA: Venture Publishing Inc.

Littlefair, C., Buckley, R. \& Wearing, S. (2002). Assessing the effectiveness of interpretive management. Presented at the Ninth International Symposium on Society and Resource Management (ISSRM), Indiana University, Bloomington, Indiana, 2-5 June.

Markwell, K. \& Weiler, B. (1998). Ecotourism and interpretation, in Uzzell, D. \& Ballantyne, R. (Eds)., Contemporary issues in heritage and environmental interpretation, London: The Stationary Office.

Morgan, J. \& Gramann, J. (1989). Predicting effectiveness of wildlife education programs: A study of students' attitudes and knowledge towards snakes. Wildlife Society Bulletin, 17 (4), 501-509.

Oliver, S., Roggenbuck, J. \& Watson, A. (1985). Education to reduce impacts in forest campgrounds. Journal of Forestry, 83 (4), 234-236.

Olson, E., Bowman, M., \& Roth R. (1984). Interpretation and non-formal environmental education in natural resource management. The Journal of Environmental Education, 15 (4), 6-10.

Roggenbuck, J. \& Berrier, D. (1982). A comparison of the effectiveness of two communication strategies in dispensing wilderness campers. Journal of Leisure Research, 14 (1), 77-89.

Roggenbuck, J. \& Williams, D. (1991). Commercial tour guide's effectiveness as nature educators. Paper presented at the World Leisure and Recreation Association Congress, Leisure and Tourism: Social and Environmental Change, Sydney, July 16-19, 651- 655.

Scraton, S. (1994). The changing world of women and leisure: feminism, 'postfeminism' and leisure. Leisure Studies, 249-61. 
Tilden, F. (1977). Interpreting Our Heritage. Chapel Hill: The University of North Carolina Press.

Urry, J. (1990). The Tourist Gaze. London: Sage Publications.

Warder, D. (1988). A management goal: effective interpretation. In Legg, M. (Ed.)., National Association of Interpretation Research Monograph (pp. 39-46).

Wearing, S. \& Bowden, I. (1999). Tourism and a changing public sector culture for parks. Australian Parks and Leisure, 1 (3), 6-8.

Wearing, S. \& Neil, J. (1999). Ecotourism: Impacts, Potentials and Possibilities. Oxford: Butterworth-Heinemann.

Wearing S. \& Hall L. (1998). Interpreting nature: different cultures, different views? 5th World Congress, Heritage Interpretation International. Quarantine Station, Sydney Harbour National Park, Sydney, 31st August - 4th September.

Wearing, B. \& Wearing S. (1996). Refocussing the tourism experience: the flaneur and the choraster. Leisure Studies, 16, 229-43.

Wearing, B. \& Wearing S. (1992). Identity and the commodification of leisure. Leisure Studies, 11, 3-18.

Wearing, B. \& Wearing, S. (1988). All in a day's leisure: gender and the concept of leisure. Leisure Studies, 7, 111-23.

Weiler, B. (1991). The Tour Leader: That 'Special' Ingredient in Special Interest Tourism, WLRA Congress. UTS Sydney, Australia, 16th-19th July. 
Table 1: Existing Interpretive Models

\begin{tabular}{|c|c|c|}
\hline & Park Management Interpretation & Adventure Guided Experiences \\
\hline Power & vested in existing park mangers and staff & $\begin{array}{l}\text { vested in the guide, who often has a } \\
\text { patriarchal power relationship with } \\
\text { participant }\end{array}$ \\
\hline Culture & $\begin{array}{l}\text { singular view of nature from hegemonic } \\
\text { park culture }\end{array}$ & $\begin{array}{l}\text { singular view of nature, based on } \\
\text { masculinised view of using nature to } \\
\text { provide adventure experiences }\end{array}$ \\
\hline Values & to preserve and conserve nature & $\begin{array}{l}\text { nature provides the basis but a backdrop } \\
\text { for the development of self }\end{array}$ \\
\hline $\begin{array}{l}\text { Place/ } \\
\text { Space }\end{array}$ & $\begin{array}{l}\text { a destination, created image and } \\
\text { experience controlled by hegemonic park } \\
\text { culture }\end{array}$ & $\begin{array}{l}\text { a place to create self and make a natural } \\
\text { place a part of everyday life }\end{array}$ \\
\hline Visitor & a voyeur to convert & $\begin{array}{l}\text { a person seeking excitement and } \\
\text { fulfilment }\end{array}$ \\
\hline Selves & $\begin{array}{l}\text { constructed as an urban visitor to } \\
\text { convert to the particular hegemonic park } \\
\text { culture, eliminates other views and } \\
\text { possible selves }\end{array}$ & $\begin{array}{l}\text { interacting experiential self seeking to } \\
\text { develop and explore through adventure } \\
\text { in the natural environment }\end{array}$ \\
\hline
\end{tabular}

Table 2: Interactive Interpretation Model 


\begin{tabular}{|l|l|l|}
\hline Power & $\begin{array}{l}\text { negotiated by the user, allowed to develop } \\
\text { own views, a more equitable distribution } \\
\text { of power }\end{array}$ & $\begin{array}{l}\text { movement away from male dominated } \\
\text { notion of adventure incorporating } \\
\text { contemplation of nature - adventure } \\
\text { takes on interaction with nature on } \\
\text { more equal terms }\end{array}$ \\
\hline Culture & $\begin{array}{l}\text { multiple views of nature - 'other' such as } \\
\text { indigenous - historic users (farming etc) }\end{array}$ & $\begin{array}{l}\text { nature not a backdrop alone to develop } \\
\text { self but a major part of the adventure } \\
\text { experience to be integrated into self }\end{array}$ \\
\hline Values & $\begin{array}{l}\text { exploring new boundaries, alternate ways } \\
\text { of valuing }\end{array}$ & $\begin{array}{l}\text { expanding beyond singular activity to } \\
\text { allow broader views and alternative } \\
\text { activity such as environmental drama } \\
\text { etc }\end{array}$ \\
\hline Place/ & $\begin{array}{l}\text { destination as a space to learn and interact } \\
\text { with the environment }\end{array}$ & $\begin{array}{l}\text { a space imbued with traditional park } \\
\text { values but open to dynamic interaction } \\
\text { with nature }\end{array}$ \\
\hline Visitor & $\begin{array}{l}\text { looking for learning and interaction with } \\
\text { others and nature }\end{array}$ & $\begin{array}{l}\text { looking for experiences and interaction } \\
\text { with nature and others }\end{array}$ \\
\hline Selves & $\begin{array}{l}\text { hybridised } \\
\text { incorporating new aspects from 'other' } \\
\text { views of nature }\end{array}$ & $\begin{array}{l}\text { Hybridised } \\
\text { a part of nature not dominating it or } \\
\text { dominated by it }\end{array}$ \\
\hline
\end{tabular}

